https://helda.helsinki.fi

\title{
Modernisation of the intermediate physics laboratory
}

\section{Kontro, Inkeri}

2018-03

Kontro , I , Heino , O , Hendolin , I \& Galambosi , S 2018, ' Modernisation of the

intermediate physics laboratory ' , European Journal of Physics , vol. 39 , no. 2 , 025702 . https://doi.org/10.1088/13

http://hdl.handle.net/10138/307299

https://doi.org/10.1088/1361-6404/aa9364

unspecified

acceptedVersion

Downloaded from Helda, University of Helsinki institutional repository.

This is an electronic reprint of the original article.

This reprint may differ from the original in pagination and typographic detail.

Please cite the original version. 


\section{Modernisation of the Intermediate Physics}

\section{Laboratory}

Inkeri Kontro, Olga Heino, Ilkka Hendolin and Szabolcs Galambosi

University of Helsinki, POB 64, FI-00014 University of Helsinki, Finland

The intermediate laboratory courses at the Department of Physics, University of Helsinki, were reformed using desired learning outcomes as the basis for design. The reformed laboratory courses consist of weekly workshops and small-group laboratory sessions. Many of the laboratory exercises are open-ended and have several possible ways of execution. They were designed around affordable devices, to allow for the purchase of multiple sets of laboratory equipment. This allowed students to work on the same problems simultaneously. Thus, it was possible to set learning goals which build on each other. Workshop sessions supported the course by letting the students solve problems related to conceptual and technical aspects of each laboratory exercise. The laboratory exercises progressed biweekly to allow for iterative problem solving. Students reached the learning goals well and the reform improved student experiences. Neither positive or negative changes in expert-like attitudes towards experimental physics (measured by E-CLASS questionnaire) were observed.

2

3

4 computational problems [1], and focusing on concepts and obtaining conceptual change does dot

5 improve problem solving skills [2].

- Traditional laboratory assignments guide students to walk through a set of instructions which 7 are known to produce an answer to a pre-set problem. These "cookbook" labs have been criticized 
8 and shown not to foster conceptual understanding [3]. To cure this, many approaches that simulate

- research have been suggested. One example is the Investigative Science Learning Environment

10 (ISLE) that prompts students to design their own lab experiments $[4,5]$.

11 The American Association of Physics Teachers recommends that the learning goals for labora12 tory courses include knowledge construction, modelling, designing experiments, developing technical 13 lab skills, analysing and visualizing data and science communication [6]. For example, Zwickl et 14 al. [7] reformed an advanced laboratory course by defining learning goals for laboratory skills and 15 designing the laboratory assignments around these goals.

16 Another important part of becoming a physicist is developing expert-like attitudes towards 17 various areas of professional life. The development of these can be monitored with attitude surveys, 18 such as the Colorado Learning Attitudes about Science Survey (CLASS) [8], or, for experimental 19 physics, the Colorado Learning Attitudes about Science Survey for Experimental Physics (E-CLASS)

2o [9]. During first year physics studies CLASS results often decline, although courses with a focus 21 on modelling and developing beliefs can lead to gains [10]. Similarly, laboratory instruction can be 22 slightly detrimental to expert-like attitudes towards experimental physics, but inclusion of open23 ended problems seems to cure this in terms of the E-CLASS [11]. Laboratory courses that focus on 24 skills seem to have a positive effect on E-CLASS scores, too [12].

25 Placing emphasis on clearly defined learning goals and recognizing that student attitudes are 26 important, we reformed the intermediate laboratory courses at the Department of Physics, Univer27 sity of Helsinki. We adapted the learning objectives detailed by Zwickl et al. [7], aiming for a pair $\mathbf{2 8}$ of courses that would serve second-year physics students and systematically build up their skills.

29 To allow for more complex problem solving independent of the instructor, the laboratory exercises sо were designed for groups of three students. We also included a weekly workshop for instruction and 31 laboratory-related problem solving exercises.

32 We discuss here the hierarchical set of learning goals and present the associated laboratory exsз periments along with the list of equipment needed. We also present the results of student satisfaction 34 surveys, an evaluation of learning outcomes and E-CLASS test scores. 
The intermediate laboratory courses (i.e. courses for 2nd or 3rd year physics students) at the

${ }_{37}$ University of Helsinki were reformed to systematically build up lab skills. Our main objective in

38 the reform was to to define clear learning objectives for the course and design exercises that would

39 lead to achieving them. The budget was to be kept as affordable as possible without compromising

40 the learning objectives.

${ }_{41} \quad$ The learning objectives were modelling, design, technical lab skills and communication, following

42 Zwickl's approach [7]. The length of the courses in fourteen weeks altogether, which led us to set

43 up three laboratory exercises for each half-semester course. That way we were able to allocate two

44 or three weeks per exercise, which allowed the students for some trial and error.

45 The exercises were graded for difficulty and the physics involved was assessed against the cur-

46 riculum to make sure the labs would not extend beyond the physics and mathematics taught at

47 lecture courses. The converse was not true - we did not aim either to cover or augment the physics

48 teaching of the lecture classes.

49 The final set of assignments had to respond to multiple pedagogical, practical and economical so aspects. In every turn, we tried to come up with exercises that could be worked out in multiple 51 ways. At the same time the physics had to be reasonably simple to allow meaningful exploration.

52 After the list of assignments was deemed sufficient, we assigned suitable learning goals to each ${ }_{53}$ and wrote a detailed grading rubric for each assignment. The level for grade 1 (pass) was set as a ${ }_{54}$ minimum requirement, 3 as a recommended level that would be sufficient for future studies, and 5 for 55 excellence that involved recursive optimization of the laboratory set-up for the particular problem.

56 The students were not required to pass every learning goal of every assignment, but all assignments

57 had to be passed with a minimum average grade of $1 / 5$. An example of the grading rubric is shown

58 in the online supplement S1.

59 The course grade was formed by lab assignment grades (75\%) and problem solving exercise 6o grades $(25 \%)$. The problem solving exercises contained visualization and analysis of data, error ${ }_{61}$ analysis and pen-and-paper calculations to recap the concepts of the physics behind the phenomena. 


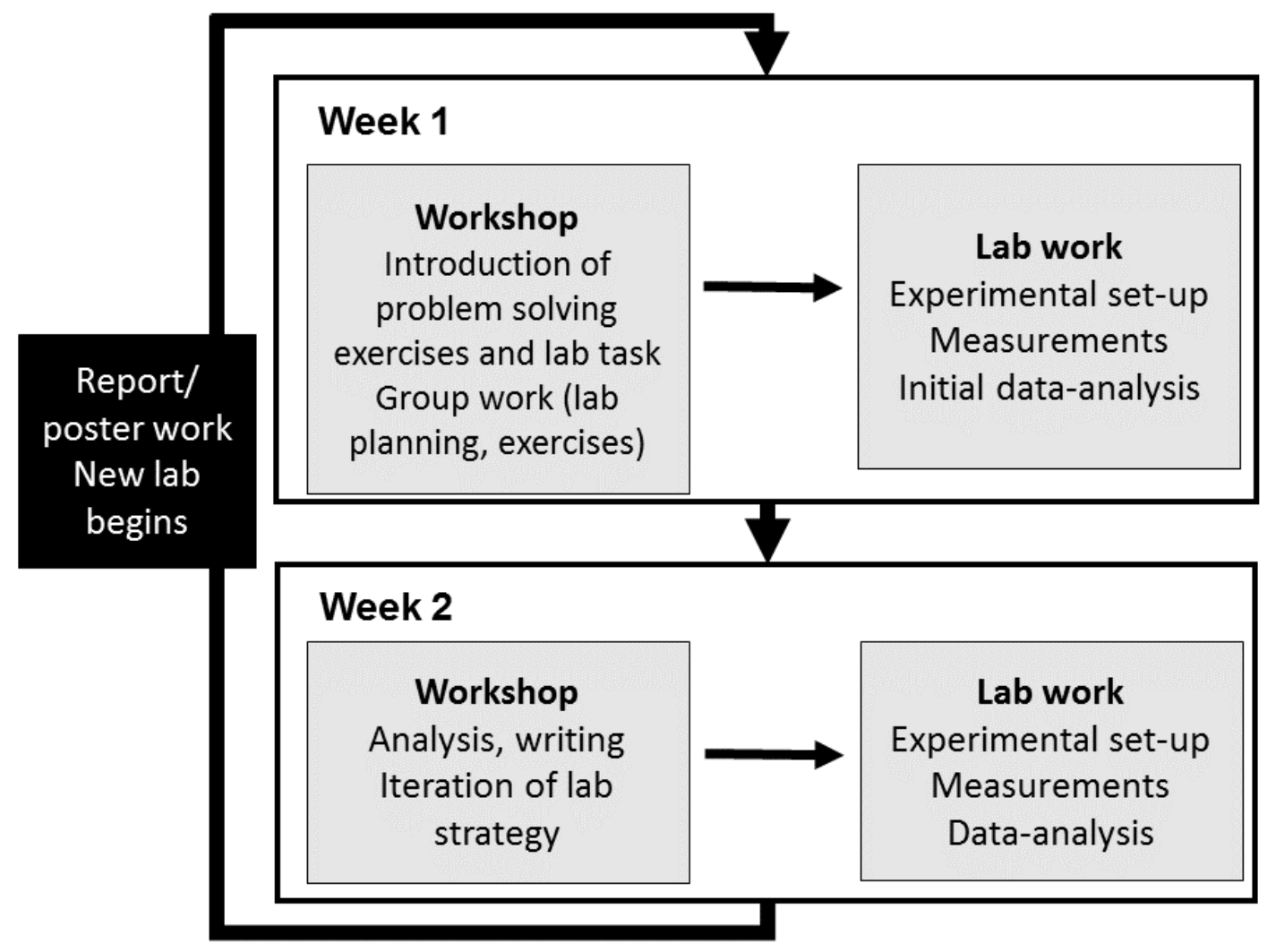

Fig. 1 The workflow of each individual laboratory exercise with accompanying exercises.

A. Schedule

64 Each course consisted of three laboratory exercises. The laboratory exercise along with the B. Elements of openness in the labs

The degree to which labs were open varied in three aspects: experiment design, approach to data 71 analysis, and application. Some labs, such as Lab I-1 and Lab I-3, were open in all these aspects 72 (see Table 1), whereas in Lab II-1, the equipment was completely fixed, but the computational 73 application open. In assignments I-2, II-2 and II-3, the students had small choices in experiment 
Table 1 Lab assignments with their associated learning goals and the problem solving exercise tasks. As a resource to instructors, this article is accompanied online with the descriptions of the lab assignments and the list of equipment and their associated costs (online supplements S2 and S3, respectively.)

\begin{tabular}{|c|c|c|}
\hline Assignment description & $\begin{array}{l}\text { Learning goal areas } \\
\text { (see section II) }\end{array}$ & Exercise activities \\
\hline $\begin{array}{l}\text { I-1: Light sensor } \\
\text { Design and build a light sensor based on a } \\
\text { light-sensitive resistor or transistor. }\end{array}$ & $\begin{array}{l}\text { - Design } \\
\text { - Application } \\
\text { - Presentation of data in } \\
\text { graphical form } \\
\text { - Presentation of results } \\
\text { in poster form }\end{array}$ & $\begin{array}{l}\text { - Visualizing data } \\
\text { - Designing DC circuits } \\
\text { - Using multimeters }\end{array}$ \\
\hline $\begin{array}{l}\text { I-2 Radiation detector } \\
\text { Examine the physical principles of a } \\
\text { scintillation-based radiation detector: Build the } \\
\text { detector from pre-made components and study } \\
\text { its function by examining the signal after each } \\
\text { component. Study the attenuation of radiation } \\
\text { as a function of thickness of the attenuating } \\
\text { material. }\end{array}$ & $\begin{array}{l}\text { - Technical lab skills, } \\
\text { incl. using an } \\
\text { oscilloscope } \\
\text { - Data analysis with } \\
\text { focus on linear fitting } \\
\text { and statistical errors. }\end{array}$ & $\begin{array}{l}\text { - Visualizing data } \\
\text { - Learning Poisson statistics } \\
\text { - Linearizing data } \\
\text { - Doing weighted and } \\
\text { unweighted linear fitting } \\
\text { with error analysis }\end{array}$ \\
\hline $\begin{array}{l}\text { I-3 Tuning fork } \\
\text { Study the shape of a vibrating tuning fork }(f= \\
440 \mathrm{~Hz}) \text {. Multiple possible approaches: direct } \\
\text { measurements via building a stroboscope, } \\
\text { photograph or video analysis, indirect } \\
\text { measurement by reflecting a laser beam from } \\
\text { the vibrating fork. Own innovations welcomed. }\end{array}$ & $\begin{array}{l}\text { - Design } \\
\text { - Data analysis }\end{array}$ & $\begin{array}{l}\text { - Learning propagation of } \\
\text { error } \\
\text { - Minimizing error by } \\
\text { experimental set-up design }\end{array}$ \\
\hline $\begin{array}{l}\text { II-1 Frying pan } \\
\text { Investigate whether a frying pan carved from a } \\
\text { single piece of aluminium would be feasible } \\
\text { regarding the temperature of its handle. } \\
\text { Use laws of convective and conductive heat } \\
\text { transfer to model the theoretical temperature } \\
\text { distribution of the handle. Determine unknown } \\
\text { parameters experimentally. }\end{array}$ & $\begin{array}{l}\text { - Curve fitting } \\
\text { - Modelling } \\
\text { - Application }\end{array}$ & $\begin{array}{l}\text { - Deriving the theoretical } \\
\text { model } \\
\text { - Curve fitting, non-linear } \\
\text { - Calculating error using } \\
\text { Monte Carlo methods }\end{array}$ \\
\hline $\begin{array}{l}\text { II- } 2 \text { Temperature of a light bulb } \\
\text { Determine the temperature fluctuations of a } \\
\text { light-bulb filament by measuring the intensity } \\
\text { fluctuations of emitted light. }\end{array}$ & $\begin{array}{l}\text { - Theoretical modelling } \\
\text { - Combining } \\
\text { experimental data with } \\
\text { theory }\end{array}$ & $\begin{array}{l}\text { - Calculating the output of a } \\
\text { black body radiator } \\
\text { - Modelling the output } \\
\text { signal of the given light } \\
\text { detector }\end{array}$ \\
\hline $\begin{array}{l}\text { II-3 The Faraday effect } \\
\text { Study the effect of magnetic field on the } \\
\text { rotation of polarization of linearly polarized } \\
\text { light. } \\
\text { Build the experimental apparatus from discrete } \\
\text { components. Devise a suitable method for } \\
\text { measuring how variations in magnetic field } \\
\text { relate to the orientation of polarization plane. }\end{array}$ & $\begin{array}{l}\text { - Theoretical modelling } \\
\text { - Extracting measurable } \\
\text { predictions from the } \\
\text { theory } \\
\text { - Using the theory to } \\
\text { optimize the experiment }\end{array}$ & $\begin{array}{l}\text { - Learning the theoretical } \\
\text { basis of the problem with } \\
\text { guidance and scaffolding as } \\
\text { needed }\end{array}$ \\
\hline
\end{tabular}


74 design, which then influenced their data analysis options.

75 In general, the degree of freedom in the laboratory decreased from course I to course II. The

76 learning goals of the latter course were focused on developing mathematical models and imple-

77 menting appropriate experiments based on the limitations, simplifications, and uncertainties of the

${ }_{78}$ models. The tasks in Course II were designed to further link the learning objectives to practices in

79 a professional physics laboratory.

\section{Examples of student solutions}

81 A. Lab I.1: Photodetector

82 The lab, in which students built a photodetector, contained the most freedom for independent 8з application (see online supplement S2) in both design choices and independent application. Stu-

84 dent reasoning for choosing an LDR or phototransistor based design followed their experience in

85 electronics. Students less familiar with the components mainly opted for LDRs, while others chose

s6 phototransistors, being aware of their better sensitivity and faster response time.

87 The calibration procedures differed vastly. Students were more prone to suggest ideas that s8 added light sources than reduced the amount of light. Many groups first suggested calibrating the 89 sensor by varying the number of light sources (e.g. identical LEDs). These students were prompted

90 to consider the directionality of the sources and the sensor. Most then tinkered with the geometry 91 of the sources, but one group asked for variable resistors to control the LED voltage. Students

$\mathbf{9 2}$ wanting to vary the source-to-detector distance faced the unavailability of point-like, uniform light

93 sources. A common solution was a screen with a small hole.

94 Some groups blocked parts of the field of view of the sensor, while others chose polarizers or ND

95 filters. Students also suggested less feasible ideas, such as varying the brightness of a laptop screen.

96 Assumption of a linear relationship between the screen brightness and the scale given by the device

97 was soon found out not to hold.

98 $\quad$ For application, students were encouraged to come up with research ideas of their own, but 99 most of them gravitated towards questions given by the instructor (see supplement S2). The most 100 popular ones were investigating the flickering of fluorescent tubes or determining the resistors' 101 response curve of the sensor they had built. Some groups opted to study ideas that they had 
abandoned as calibration procedures, for example looking at $(r, I)$ for an unmodified source, or the intensity emitted by a laptop screen as a function of screen brightness.

A common challenge in the application phase was that the phenomenon to be studied was, in fact, not in the calibrated region. Some students switched or modified research questions, while others redid their calibration. Some extrapolated their calibration curves. Students were encouraged to think about the implication of this for the reliability of the results.

\section{B. Lab II.1: The frying pan}

The students were asked to investigate whether a frying pan from a single piece of aluminium was feasible (for a complete description, see online supplement S2). In contrast to the light detector lab, this assignment contained little open-ended work in the laboratory. In the laboratory section, a fixed set-up was used to determine fit parameters for a differential equation.

However, the students had choices in the modelling part and several strategies emerged. Less confident students simply varied the length or the diameter of the handle, while more ambitious students experimented with different geometries. Students who calculated results with hollow handles were very eager to provide all the approximations involved in their model, such as the temperature inside the hollow core. A particularly nifty, albeit rare way of solving the problem was solving for the ratio of the cross-section and the surface area of the handle and basing the design on that.

Adjusting the model to suit the problem was a common issue. Students had generally solved the heat conduction equation with a constant heat flow as a boundary condition, and proceeding from there to a temperature for frying proved complicated. Despite the abstractness of the differential equation and the simplicity of the lab work, students related the problem to its real world counterpart. Their reports contained citations e.g. for the output power of electrical stoves or the ideal temperatures for frying pancakes, depending on the boundary conditions used.

\section{Outcome}

\section{A. Learning outcomes}

Learning outcomes were assessed with a grading rubric, specific for each laboratory assignment. Grading was done wholly by the staff, except for Lab I-1, where a poster (for a report) was peer- 

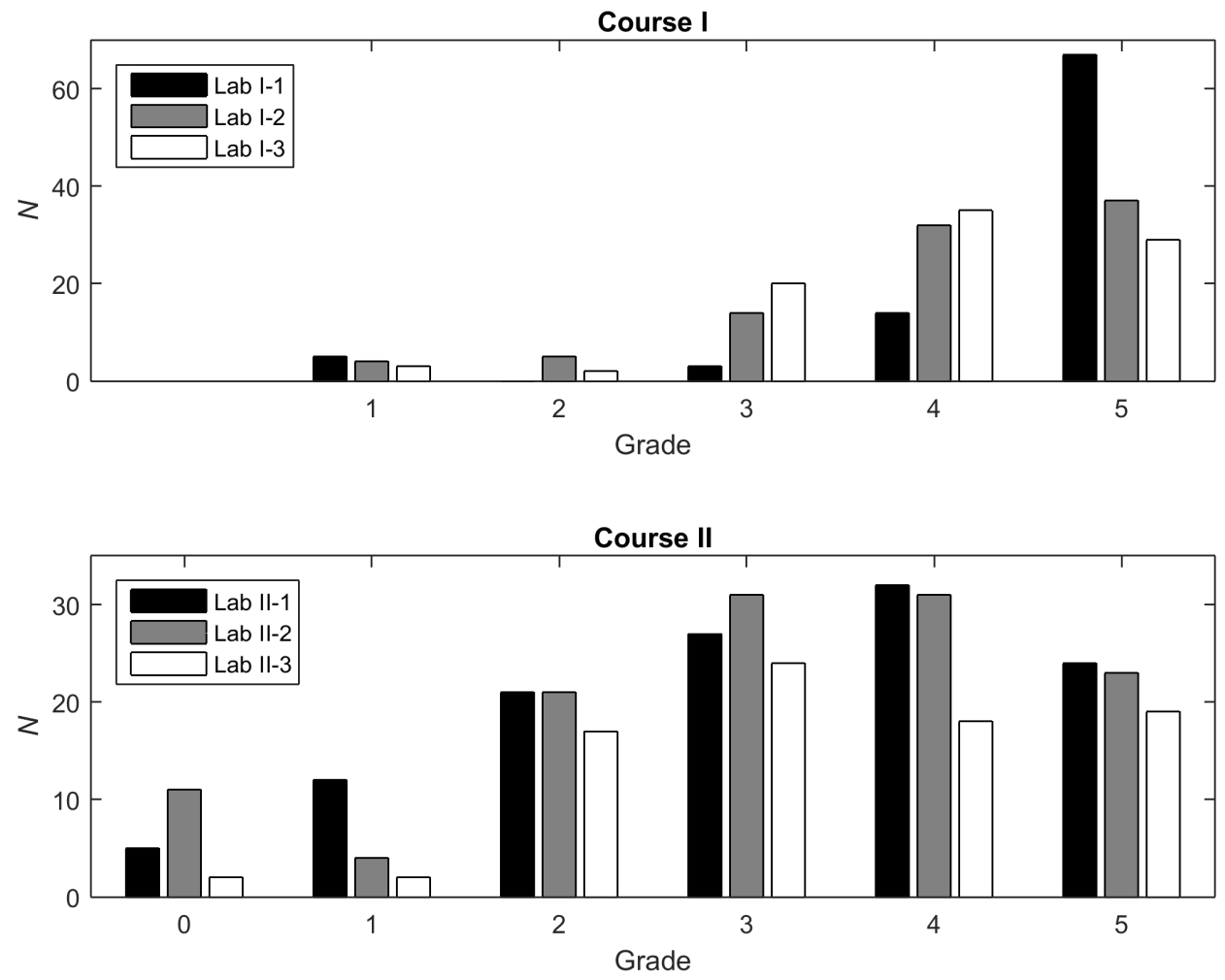

Fig. 2 The distribution of grades for Course I (top, $N=11$ ) and Course II (bottom, $N=121$ ). The labs were graded on a scale of $0-5$, where 1-5 are passing grades ( 5 being the highest)

reviewed.

With the exception of Lab I-1, the average grades of all lab exercises were almost equal. Grades for Lab I-1 deviate from this, likely due to the peer review and also the smoothing caused by assessing the group's final work instead of individual reports. Grade inflation from peer review was modest, and the benefits of making the students examine in detail and apply a grading rubric were, in our opinion, more important.

In general, student performances were at a satisfactory level. The majority of students reached grade 3 - the level sufficient for future studies (see Figure 2 for the grade distribution and online supplement S1 for an example of the grading rubric). Students who failed, but who had made a sincere effort, were given an opportunity to amend reports for a passing grade. 
Table 2 E-CLASS average score for the full-length courses in $2016(N=32)$ and $2017(N=29)$, E-CLASS average and standard error of the mean. "Own" refer to questions phrased "What do you think?" and "Phys" to questions phrased "What would an experimental physicist say?"

$$
\begin{array}{lcc}
\text { Test } & \text { Own } & \text { Phys } \\
\text { pre (2016) } & 15.2 \pm 1.2 & 23.4 \pm 0.7 \\
\text { post (2016) } & 15.8 \pm 1.023 .0 \pm 0.7 \\
\text { pre (2017) } & 14.8 \pm 1.022 .1 \pm 0.8 \\
\text { post (2017) } & 15.1 \pm 1.123 .3 \pm 0.7
\end{array}
$$

B. E-CLASS results

We used a verified Finnish translation of the E-CLASS survey [9] to study student attitudes.

The students were asked to fill in the survey at the beginning of Course I and at the end of Course II. Only matched pairs from courses I and II were included in the analysis. The students were asked to answer the questions both based on what they thought themselves and how they would expect an experimental physicist to answer on a Likert scale (strongly disagree - strongly agree). The responses were graded -1 points for disagreement with the expert answer, 0 points for a neutral answer and 1 point for agreement with the expert answer [9]. The average total scores are shown in Table 2.

There was no significant change in students' expert-like attitudes during the course in either their personal or professional views. The average scores for each question for 2016 are shown in Figure 3.

The students' views differed from percieved expert views in particular for statement 14 ("When doing an experiment I usually think up my own questions to investigate", see Figure 3). The pretest was collected during Lab I-1, which explicitly prompts students to pick a problem of their choosing, but students clearly did not consider this as "usually thinking up their own questions". Also for statement 10, "Whenever I use a new measurement tool, I try to understand its performance limitations", students admitted to not working as they expect experts to do. This is in stark contrast to e.g. statements 1 ("When doing an experiment, I try to understand how the experimental setup 


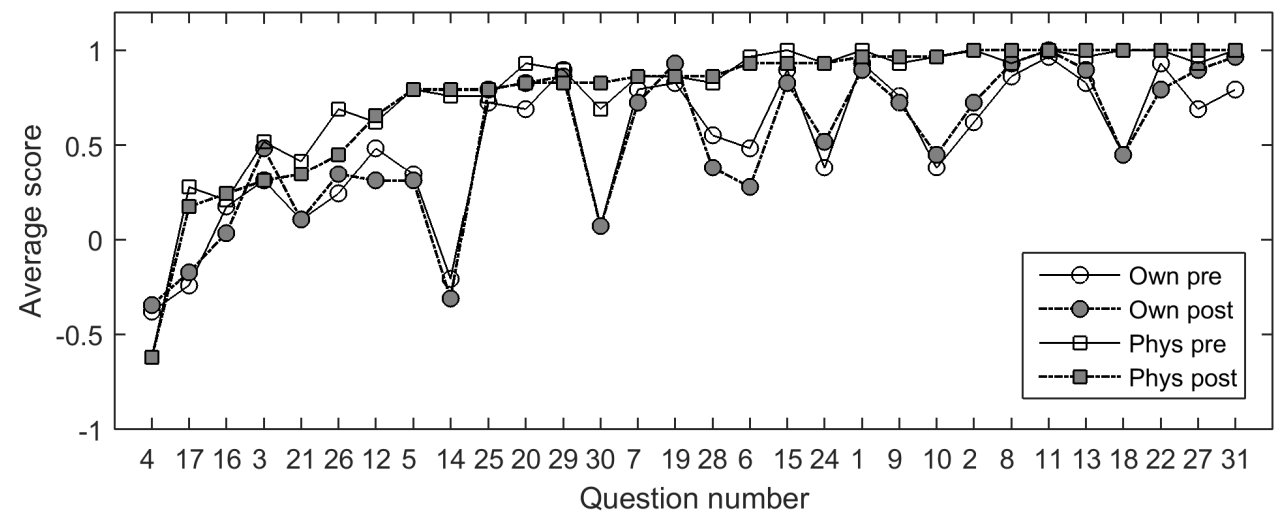

Fig. 3 The average scores of each E-CLASS question in 2016. Answers coded as "Own" are scores for the questions "What do you think?" and answers coded "Phys" are for scores for the questions "What would an experimental physicist say?" Questions are sorted according to post-instruction scores for physicist questions.

works") and 8 ("When doing an experiment, I try to understand the relevant equations"), where students say they act in an expertlike manner.

Our students have a moderately high understanding on what experimental physicists feel about physics experiments (overall, $77 \%$ agreement with experts). Reassuringly, students answers for their own work did not differ from perceived expert opinion and was on average favourable in the statements 20 and 25: "I enjoy building things and working with my hands" and "Nearly all students are capable of doing a physics experiment if they work at it" (see Figure 3). The trend is that students are not confident that they can resolve problems without guidance. They try to understand the experimental set-up and the theory, but pay less attention to the way the devices work. However, they enjoy working in the lab and believe they could be good at doing research. Also, the students, by their own admission, felt that the course contents are highly likely to be useful in their future studies.

Wilcox and Lewandowski [11] found that the inclusion of open-ended laboratory exercises improved E-CLASS scores while traditional lab exercises had a small but negative effect on them. In 2 a later study, they also found that laboratory courses that focus on building skills have a positive effect on E-CLASS scores, whereas laboratory courses that focus on physics concepts have a negative effect, and courses that focus on both induce no change [12]. Despite our course being focused on 

177 of theory and experiment on Course II.

178 required good technical and computational skills.

\section{Course feedback} previous courses.

skills, our results show no change. From the E-CLASS results, the courses seem to yield similar results as courses that focus on both skills and concepts, which may reflect the focus on the interplay

The discrepancy between students' own beliefs and what they think experts believe has been noted earlier on in the context of CLASS [13]. Our course reform was obviously not able to close this gap, even though some of the course elements have been found to foster expert-like attitudes in previous studies. One of the reasons for this might be that the E-CLASS post-test was administered after Course II, where the assignments were not open-ended and had less flexibility in the experimental set-up. Especially the last laboratory exercise was conceptually difficult, and it also

We collected student feedback at the end of each course. Students evaluated statements on a 5-point Likert scale (strongly disagree to strongly agree) and answered free-form questions about the lab exercises, the interplay between workshops, tutorials and lab assignments, and possible improvements to the course structure. The feedback procedure was familiar to students from numerous

Students evaluated e.g. the level of their prior knowledge, the difficulty of the course, the course workload and the course as a whole (Table 3). There were no significant differences in how difficult the course was judged by 2nd, 3rd, 4th year and older students. (Despite this being a course aimed at 2nd and 3rd year students, many older students also attended, either due to changing specialization, delayed studies or being Physics minors.) Satisfyingly, the students found their prior knowledge sufficient but the course demanding. Overalll, the students found the course highly interesting and highly likely to be useful in their future studies.

\section{Conclusions}

Designing good and affordable laboratory courses can be difficult. Laboratory courses can discourage expert-like attitudes if they focus on closed problems or merely physics concepts, and a known obstacle for setting up new labs can be the costly equipment. 
Table 3 Course feedback averages from 2016 for statements answered with Likert scale $(1=$ strongly disagree, $5=$ strongly agree)

\begin{tabular}{lcc}
\hline \hline Statement & Course I (N =48) & Course II (N =45) \\
"My prior knowledge was sufficient" & $4.0 \pm 0.8$ & $3.8 \pm 0.9$ \\
"The course was easy" & $2.8 \pm 0.7$ & $2.4 \pm 0.7$ \\
"The course demanded little work compared to ECTS" & $2.3 \pm 0.8$ & $2.0 \pm 0.5$ \\
"As a whole, the course deserves the grade" & $4.2 \pm 0.7$ & $4.0 \pm 0.6$ \\
\hline \hline
\end{tabular}

212 and they showed high accountability.

\section{List of online supplements}

${ }_{214} \mathbf{S 1}$ : An example of a grading rubric

Our laboratory courses were designed to address these problems. The laboratory exercises were mostly open-ended with no single right answers, and typically several different approaches were possible. We also wanted to foster collaboration skills in students and provide room for iteration of measurement strategy. These goals were reached with a very reasonable budget.

While we did not see gains in expert-like attitudes towards experimental physics, as measured by E-CLASS, we also saw no losses. Through the E-CLASS, we gained the knowledge that students have a fairly good grasp of what experimental physicists think when doing experiments.

Overall, the reform was a success. The majority of students achieved the set learning goals and student feedback shows that the course difficulty level was appropriate: easy to begin but demanding hard work in a rewarding way. Students expect their learning to be useful in their future studies, and they showed high accountability.

S2: Full lab instructions for each exercise

216 S: A list of equipment and their cost for the lab exercises \\ Acknowledgments}

We thank Prof. Hanna Vehkamäki for discussion of the lab exercises, Dr. Seppo Andersson for the list of equipment and Prof. Ismo Koponen for discussion on this manuscript. 
[1] Hake, R.R. "Interactive-engagement versus traditional methods: A six-thousand-student survey of mechanics test data for introductory physics courses," American Journal of Physics, Vol. 66, No. 1, 1998, pp. $64-74$

[2] McDaniel, M.A., Stoen, S.M., Frey, R.F., Markow, Z.E., Hynes, K.M., Zhao, J. and Cahill, M.J., "Dissociative conceptual and quantitative problem solving outcomes across interactive engagement and traditional format introductory physics," Physical Review Physics Education Research, Vol. 12, No. 2, 2016, pp. 020141-1-16.

[3] Royuk, B. and Brooks, D.W. "Cookbook procedures in MBL physics exercises," Journal of Science Education and Technology, Vol. 12, No. 3, pp. 317-324.

[4] Etkina, E., Murthy, S. and Zou, X, "Using introductory labs to engage students in experimental design," American Journal of Physics, Vol. 74, 2006, pp. 979-

[5] Karelina, A. and Etkina, E. "Acting like a physicist: Student approach study to experimental design," Physical Review Special Topics - Physics Education Research, Vol. 2, No. 2, 2007, p. 020106.

[6] AAPT Committee on Laboratories, "AAPT Recommendations for the Undergraduate Physics Laboratory Curriculum," Phys. Teach., Vol. 53, 2015, pp. 253âĂŞ253.

[7] Zwickl, B.M., Finkelstein, N. and Lewandowski, H.J. "The process of transforming an advanced lab course: Goals, curriculum, and assessments," American Journal of Physics, Vol. 81, No. 1, 2013, pp. 63-70. doi: 10.1119/1.476889

[8] Adams, W.K., Perkins, K.K., Podolefsky, N.S., Dubson, M., Finkelstein, N.D. and Wieman, C. E. "New instrument for measuring student beliefs about physics and learning physics: The Colorado Learning Attitudes about Science Survey," Physical Review Special Topics - Physics Education Research, Vol. 2, No. 1, 2006, p. 010101.

[9] Zwickl, B.M., Finkelstein, N. and Lewandowski, H.J. "Development and Validation of the Colorado Learning Attitudes about Science Survey for Experimental Physics," 2012 Physics Education Research Conference, Vol. 1513, 2013, pp. 442-445.

[10] Madsen, A., McKagan, S.B. and Sayre, E.C. "How physics instruction impacts students' beliefs about learning physics: A meta-analysis of 24 studies," Physical Review Special Topics - Physics Education Research, Vol. 11, No. 1, 2015, p. 010115

[11] Wilcox, B.R. and Lewandowski, H.J. "Open-ended versus guided laboratory activities: Impact on students' beliefs about experimental physics," Physical Review Physics Education Research, Vol. 12, No. 
$251 \quad 2$, p. 020132

252 [12] Wilcox, B.R. and Lewandowski, H.J. "Developing skills versus reinforcing concepts in physics labs: In-

253 sight from a survey of students' beliefs about experimental physics," Physical Review Physics Education

$254 \quad$ Research, Vol. 13, No. 1, p. 010108

255 [13] Gray, K.E., Adams, W.K., Wieman, C.E., and Perkins, K.K. "Students know what physicists believe,

256

but they don't agree: A study using the CLASS survey" Phys. Rev. ST Phys. Educ. Res. 4, 020106 